http://jmscr.igmpublication.org/home/ ISSN (e)-2347-176x ISSN (p) 2455-0450 crossref DOI: https://dx.doi.org/10.18535/jmscr/v8i5.69

\author{
D) Journal Of Medical Science And Clinical Research \\ IGM Publication \\ An Official Publication of IGM Publication
}

\title{
Evaluation of Endometrial Thickness in Females with Post Menopausal Bleeding
}

Authors

\author{
Dr Chetna Dhamija, Dr CL Thukral
}

Sri Guru Ram Das Institute of Medical Sciences and Research Vallah Sri Amritsar

\begin{abstract}
The study evaluated the endometrial thickness in post menopausal bleeding subjects with trans-vaginal Itrans-abdominal ultrasonography and further the endometrial thickness was correlated with histopathological findings. This diagnostic study included 50 females who presented with postmenopausal bleeding. All females were subjected to transvaginal ultrasonographic evaluation of the endometrial thickness. These females further underwent dilatation and curettage procedure to obtain endometrial curettings which were subjected to histopathological examination. In the present study 50 females between ages 44 to 68 years were included. Out of the total 50 females who presented with post menopausal bleeding 9 females were diagnosed with endometrial carcinoma, 18 females with endometrial hyperplasia, 16 with benign endometrial glands, 6 with atrophic endometrium and 1 with endometrial polyp on histopathological examination after dilatation and curettage. Mean endometrial thickness was significantly more in cases of malignancy as compared to benign conditions $(21.83 \mathrm{vs} 11.32 \mathrm{~mm}$; $p<0.01$ ). Endometrial thickness was observed to be a significant predictor for malignancy (Area under ROC was 0.844; p-value <0.01) with sensitivity and specificity of $88.9 \%$ and $63.4 \%$ at a cut-off of 11.7 mm. Although transvaginal sonography endometrial thickness can be used as a screening tool in discriminating normal from abnormal endometrium but cannot differentiate benign from malignant endometrium.
\end{abstract}

\section{Introduction}

Postmenopausal bleeding is defined as bleeding occurring 12 months after cessation of menstruation due to ovarian failure in women not taking hormone replacement therapy. However vaginal bleeding occurring anytime after 6 months of amenorrhea in a woman of menopausal age should be considered as postmenopausal bleeding and investigated. ${ }^{1}$

There has been a steady increase in the incidence of endometrial cancer over recent years. Uterine curettage is mandatory to exclude endometrial cancer in women presenting with post-menopausal bleeding which is the initial presenting symptom in 75 to $90 \%$ of the cases .However dilatation and curettage is an invasive procedure associated with morbidity and only $10 \%$ of females are diagnosed with malignancy. Therefore there arises a need for non invasive screening method to diagnose endometrial malignancies which are associated with good prognosis. ${ }^{2}$

Measurement of endometrial thickness by ultrasonography is by far the most convenient, non-invasive method for diagnosis of the endometrial pathologies. 


\section{Material and Methods}

This diagnostic study comprised of 50 women who presented with postmenopausal bleeding. Women with uterine fibroids, adenomyosis, Carcinoma cervix and any general disease that could affect pelvic blood flow were excluded from the study.

The sonography was performed using Voluson E8 Expert BT09 transvaginal transducer with frequency of 5-7 Mhz after taking .informed consent from the patient Endometrial thickness was measured in longitudinal section from the anterior subendometrial hypoechoic zone (halo) to the opposite side, including two endometrial layers.

Operative procedure of obtaining endometrial curetting was undertaken under short general anesthesia with informed consent and preanesthetic check up. The curettings were sent for histopathological examination in $10 \%$ formalin solution. The data obtained from ultrasound and Doppler examinations were compared to the results of histopathological study and clinical findings.

\section{Results}

The statistical analysis was carried out using statistical Package for social sciences [IBM SPSS version 23]. Mean and standard deviation were calculated for normally distributed data. The endometrial thickness was compared with histopathological findings post dilatation and curettage .Student $\mathrm{T}$ test for significance was applied to find the significance of sonographic parameters in detecting endometrial malignancies. All statistical tests were two sided and significance level were taken as of $\mathrm{P}<$ 0.01.Further ROC curves were used to obtain the ideal cut off for endometrial thickness .Sensitivity and specificity at ideal cut off was determined using ROC curve.

Mean age of the study cases was $52.38+/-7.97$ years with $82 \%$ of the cases between age of 41-60 years. In our study age of females with malignant endometrium was more than that of females with benign endometrium (55.4+/-9.1 as compared to $51.6+/-7.5)$. Females with malignant endometrium had more number of years elapsed since menopause $(9+/-5.6)$ whereas those with benign endometrium had less number of mean years elapsed since menopause $(6+/-5)$ (table 1$)$

Out of total 50 cases, $82 \%$ had benign lesions while $18 \%$ had malignant lesions.9 females were diagnosed with endometrial carcinoma, 18 females with endometrial hyperplasia, 16 with benign endometrial glands, 6 with atrophic endometrium and 1 with endometrial polyp on histopathological examination after dilatation and curettage (table 2) Mean endometrial thickness was significantly more in cases of malignancy as compared to benign conditions (21.83 vs 11.32 $\mathrm{mm} ; \mathrm{p}<0.01$ ). (table 3)

Endometrial thickness was observed to be a significant predictor for malignancy (Area under ROC was 0.844 ; p-value $<0.01$ ) with sensitivity and specificity of $88.9 \%$ and $63.4 \%$ at a cut-off of $11.7 \mathrm{~mm}$. (table 4)

Table 1 Distribution of study cases as per Age group

\begin{tabular}{|l|l|l|}
\hline Age group (yrs) & $\mathbf{N}$ & \% \\
\hline $\mathbf{4 1 - 5 0}$ & 26 & $52.0 \%$ \\
\hline $\mathbf{5 1 - 6 0}$ & 15 & $30.0 \%$ \\
\hline $\mathbf{6 1 - 7 0}$ & 8 & $16.0 \%$ \\
\hline$>\mathbf{7 0}$ & 1 & $2.0 \%$ \\
\hline Total & 50 & $100.0 \%$ \\
\hline \multicolumn{2}{|l|}{ Mean age - 52.38 +/-7.97 years } \\
\hline
\end{tabular}

Table 2: Distribution of endometrial pathologies

\begin{tabular}{|l|c|c|}
\hline Histopathology & N & \% \\
\hline Adenocarcinoma & 9 & $18.0 \%$ \\
\hline Atrophic Endometrium & 6 & $12.0 \%$ \\
\hline Hyperplasia & 18 & $36.0 \%$ \\
\hline Polyp & 1 & $2.0 \%$ \\
\hline Proliferative Endometrium & 14 & $28.0 \%$ \\
\hline Secretory Endometrium & 2 & $4.0 \%$ \\
\hline Total & 50 & $100.0 \%$ \\
\hline
\end{tabular}




\section{JMSCR Vol||08||Issue ||05||Page 380-384||May}

Table 3 Mean endometrial thickness in benign and malignant cases

\begin{tabular}{|c|c|c|c|c|c|}
\hline Variables & Diagnosis & $\mathbf{N}$ & Mean & SD & p-value \\
\hline \multirow{2}{*}{$\begin{array}{l}\text { Endometrial } \\
\text { Thickness }\end{array}$} & Benign & 41 & 11.32 & 7.06 & \multirow{2}{*}{$<0.01$} \\
\hline & Malignant & 9 & 21.83 & 7.79 & \\
\hline
\end{tabular}

Table 3 ROC analysis for endometrial thickness

\begin{tabular}{|c|c|c|c|c|c|}
\hline \multicolumn{6}{|c|}{ Area Under the Curve } \\
\hline \multirow{2}{*}{$\begin{array}{l}\text { Test Result } \\
\text { Variable(s) }\end{array}$} & \multirow{2}{*}{ Area } & \multirow{2}{*}{ SE } & \multirow{2}{*}{ p- value } & \multicolumn{2}{|c|}{$95 \% \mathrm{CI}$} \\
\hline & & & & Lower Bound & Upper Bound \\
\hline ET & 0.844 & 0.065 & $<0.01$ & 0.717 & 0.972 \\
\hline
\end{tabular}

\begin{tabular}{|l|c|c|}
\hline Ideal Cut-off & Sensitivity & Specificity \\
\hline $\mathbf{1 1 . 7}$ & $88.9 \%$ & $63.4 \%$ \\
\hline
\end{tabular}
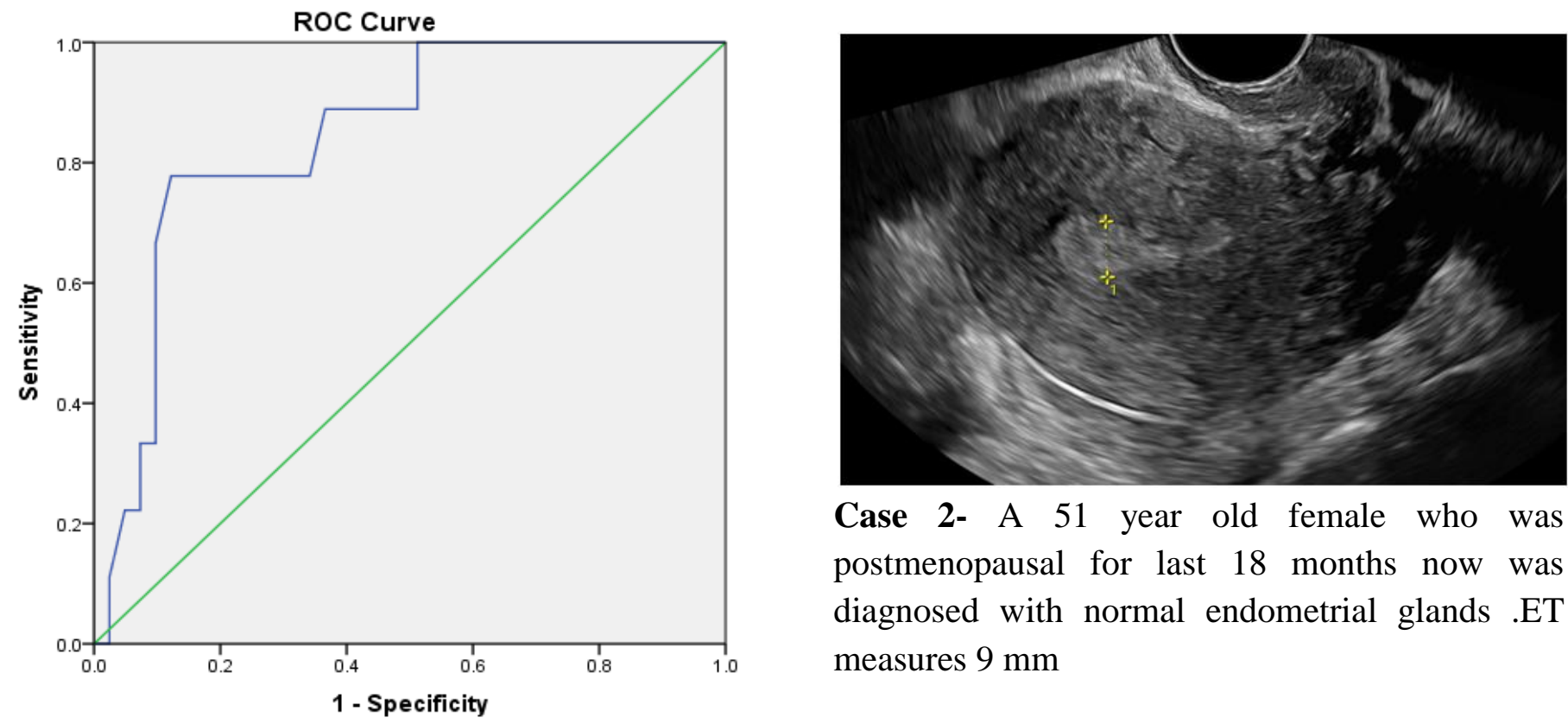

Case 2- A 51 year old female who was postmenopausal for last 18 months now was diagnosed with normal endometrial glands .ET measures $9 \mathrm{~mm}$

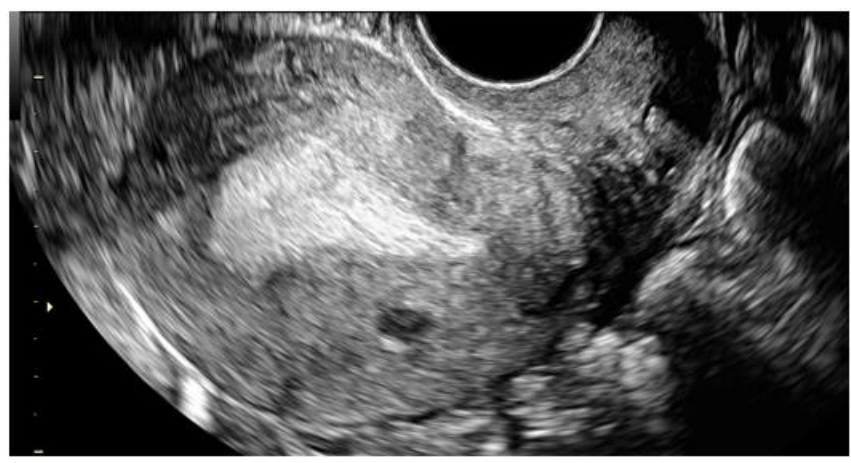

Case 3 - A 49 year old female who was diagnosed with endometrial hyperplasia on histopathology .ET measures $15 \mathrm{~mm}$

Case 1-A 52 year old female who was diagnosed with malignancy .ET measures $33 \mathrm{~mm}$ 


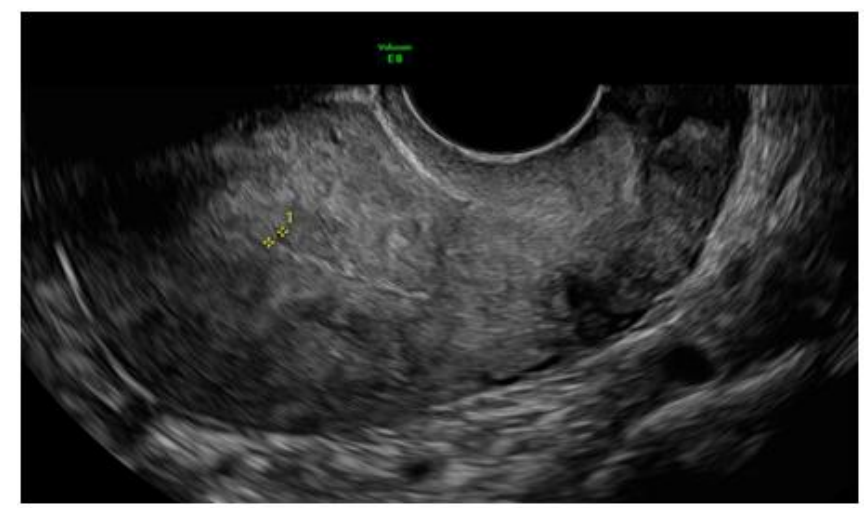

Case 4- A 56 year old female who was postmenopausal for 7 years now presented with an episode of spotting .The endometrial thickness was $3 \mathrm{~mm}$.

\section{Discussion}

In India incidence of endometrial cancer is preceeded by cervical and ovarian cancers. In our study Incidence of endometrial carcinoma was 18 $\%$ (9 out of 50 females) It is higher as compared to previous studies which have reported an incidence of $10 \%$. Bezeniunka et $\mathrm{al}^{5}$ nevertheless have reported a $22.6 \%$ rate of malignancy in patients with postmenopausal bleeding

Rate of malignancy is variable due to patient characteristics like age, time since onset of menopause. In our study the mean age of females diagnosed with malignant endometrium was higher as compared to females diagnosed with benign endometrium. Howver Develinku et al ${ }^{6}$ also have stated that incidence of endometrial cancer increases as patients age increases. In our study females diagnosed with malignant endometrium had more number of mean years elapsed since menopause. Novak's Gynaecology states that peak incidence of endometrial cancer occurs 10-15 years after average age of menopause.

In our study mean endometrial thickness was significantly more in cases of malignancy (21.83 $+/-7.79)$ as compared to benign conditions (11.32 +/-7.06); Using ' $\mathrm{T}$ ' test significant correlation was found between endometrial pathology and endometrial thickness $(p<0.01)$. These findings are higher than those with Bano et $\mathrm{al}^{7}$ The mean endometrial thickness in cases with benign endometrium was $9.2 \mathrm{~mm}$ (S.D. $=4.67 \mathrm{~mm}$ ) and in cases with malignant endometrium was. 16.36 $(\mathrm{S} . \mathrm{D}>=7.1 \mathrm{~mm})$ whereas another study showed mean endometrial thickness as $8 \mathrm{~mm} \pm 9 \mathrm{~mm}$ in absence of cancer and $20 \mathrm{~mm} \pm 9 \mathrm{~mm}$ in presence of cancer .

The sonographic measurements of endometrium with a thickness of greater than $5 \mathrm{~mm}$ exhibited $100 \%$ sensitivity, $22 \%$ specificity, $15 \%$ positive predictive value, and $100 \%$ negative predictive value in our study. Our findings are in concordance with various studies which have used 3-5 mm endometrial echo as a cut-off value for transvaginal ultrasonography with an extremely high negative predictive value (greater than 99\%). The endometrial thickness was observed to be a significant predictor for malignancy (Area under ROC was 0.844 ; p-value $<0.01$ ) with sensitivity and specificity of $88.9 \%$ and $63.4 \%$ at a cut-off of $11.7 \mathrm{~mm}$. According to the ROC curve the ideal cut off is $11.7 \mathrm{~mm}$ which has more specificity as compared to the 3-5 mm cut off used commonly by previous researchers but it comes at the cost of decreased sensitivity.

So we reach a point where if we use ET value 3$5 \mathrm{~mm}$ we are less likely to miss any malignancy but it will be associated with a high false positive rate. A large number of females will undergo dilatation and curettage and less number of females would be diagnosed with malignancy like in our study. If we use the ideal cut off which is $11.7 \mathrm{~mm}$ as provided by the ROC curve we achieve better specificity ie $63.4 \%$ however the sensitivity is compromised from $100 \%$ to $88.9 \%$ .There will be a higher false negative rate at this cut off. In our study if $11.7 \mathrm{~mm}$ ideal cut off is used we will miss one case of malignancy in our study.

These considerations underline the fact that ET measurements alone will not decrease unwarranted invasive procedures in about one third to one-half of the cases, due to high false positive results. Using a $5 \mathrm{~mm}$ endometrial thickness as a cut-off value is a reliable method to exclude the possibility of malignancy in 
postmenopausal bleeding. However it is not diagnostic of any particular pathology.

\section{Bibliography}

1. Padubidri, V.(2014). Shaws Textbook of Gynaecology $.16^{\text {th }}$ ed. Elsvier Health Sciences APAC,pp.65-79.

2. Abdel Maboud, N. and Elsaid, H. (2015). Role of transvaginal ultrasonography and colour Doppler in the evaluation of postmenopausal bleeding. The Egyptian Journal of Radiology and Nuclear Medicine, 46(1), pp.235-43.

3. Kurjak A, Shalan H, Sosic A, Benic S, Zudenigo D, Kupesic S et al. Endometrial carcinoma in postmenopausal women: Evaluation by transvaginal color Doppler ultrasonography. Am J of Obstet Gynecol. 1993;169(6):1597-603.

4. Bourne T, Campbell S, Steer C, Royston P, Whitehead M, Collins W. Detection of endometrial cancer by transvaginal ultrasonography with color flow imaging and blood flow analysis: A preliminary report. Gynecologic Oncology. 1990;40(3):253-9.

5. Incim Bezircioglu, Ali Baloglu, Burcu Cetinkaya, Seyran Yigit and Ergun Oziz, The diagnostic value of the Doppler ultrasonography in distinguishing the endometrial malignancies in women with postmenopausal bleeding, Archives of Gynecology and Obstetrics, 10.1007/s00404-011-2159-4, 285,

5, (1369-1374), (2011).

6. Dijkhuizen FP, Parolmann HA, Heiaz AP and Potters AE: The accuracy of transvaginal ultrasonography in the diagnosis of endometrial abnormalities. Obstest. Gynecol, 87 (3):345-349, 1996.
7. Bano I, Mittal G, Khalid M, Akhtar N, Arshad Z. A study of endometrial pathology by transvaginal colour Doppler ultrasonography and its correlation with histopathology in post-menopausal women. Indian Med Gazette 2013:134-9.

8. Weiner Z, Beck D, Rottem S, Brandes J, Thaler I. Uterine artery flow velocity waveforms and color flow imaging in women with perimenopausal and postmenopausal bleeding: Correlation to endometrial histopathology. Acta Obstetricia et Gynecologica Scandinavica. 1993;72(3):162-6.

9. Epstein E, Skoog L, Isberg P, De Smet F, De Moor B, Olofsson P et al. An algorithm including results of gray-scale and power Doppler ultrasound examination to predict endometrial malignancy in women with postmenopausal bleeding. Ultrasound Obstet Gynecol. 2002;20(4):370-6.

10. Alcázar J, Castillo G, Mínguez J, Galán M. Endometrial blood flow mapping using transvaginal power Doppler sonography in women with postmenopausal bleeding and thickened endometrium. Ultrasound Obstet Gynecol. 2003;21(6):583-8. 